\title{
The LOM application profile for agricultural learning resources of the CGIAR
}

\section{Thomas Zschocke*}

Human Capacity Building Section,

United Nations University Institute for Environment and Human Security, UN Campus, Hermann-Ehlers-Str. 10, 53113 Bonn, Germany

E-mail: zschocke@ehs.unu.edu

${ }^{*}$ Corresponding author

\section{Jan Beniest and Courtney Paisley}

Training Unit,

World Agroforestry Centre (ICRAF),

United Nations Avenue, P.O. Box 30677 ,

00100 Nairobi, Kenya

E-mail: j.beniest@cgiar.org

E-mail: courtneypaisley@gmail.com

\section{Jehad Najjar and Erik Duval}

\author{
Computer Science Department, \\ Katholieke Universiteit Leuven, \\ Celestijnenlaan 200 A, 3001 Leuven, Belgium \\ E-mail: jehad@najjar.be \\ E-mail: Erik.Duval@cs.kuleuven.be
}

\begin{abstract}
The international agricultural research centres of the CGIAR have established a repository for agricultural learning resources in collaboration with the ARIADNE Foundation. To make it easier to find these resources, an application profile, CG LOM Core, was developed on the basis of the IEEE Learning Object Metadata (LOM) standard. It defines the collection of metadata elements and value spaces drawn from other namespaces, adapted to the requirements of the CGIAR in describing and sharing their learning resources with an international audience. It maintains increased semantic interoperability within the CGIAR community and preserves compatibility with other repositories outside of the CGIAR.
\end{abstract}

Keywords: LOM; learning object metadata; application profile; learning technology standardisation.

Reference to this paper should be made as follows: Zschocke, T., Beniest, J., Paisley, C., Najjar, J. and Duval, E. (2009) 'The LOM application profile for agricultural learning resources of the CGIAR', Int. J. Metadata, Semantics and Ontologies, Vol.

Biographical notes: Thomas Zschocke received his Doctor of Education (EdD) from the University of Massachusetts, Amherst, USA, in 2002. He is currently the Head of the Human Capacity Building Section at the United Nations University Institute for Environment and Human Security (UNU-EHS), Bonn, Germany. His current research interests include learning objects and instructional design, topic-based authoring and DITA.

Jan Beniest has an Agricultural Engineering (Ir) Degree in Horticulture from Ghent State University (1975). He is the Training Unit Manager and Principal Training Scientist at the World Agroforestry Centre (ICRAF), Nairobi, Kenya. He is responsible for the centre's training activities and has an interest in e-learning as an additional approach to achieve the centre's capacity building and strengthening objectives.

Courtney Paisley has an MSc in Environmental Governance from the University of Manchester. She worked as a Research Associate at the World Agroforestry Centre (ICRAF) from 2004 to 2006. 
Jehad Najjar is a post-doctoral researcher in the Hypermedia and Databases Research Group of the Computer Science Department of the Katholieke Universiteit Leuven, Belgium. His research interests are in technology-enhanced learning, learning objects, metadata, attention metadata, interoperability, application profiles, evaluation of the actual use of Learning Object Metadata (LOM), usability engineering and human-computer interaction in general. He co-authored the Contextualised Attention Metadata (CAM) specifications: a schema and framework for tracking and managing data about user attention and interest across systems and contexts.

Erik Duval is a Professor in the research unit on Hypermedia and Databases at the Computer Science Department of the Katholieke Universiteit Leuven, Belgium. His research interests include metadata in a wide sense, LOM in particular, and how they enable finding rather than searching; a global learning infrastructure based on open standards; human-computer interaction in general, and in a learning or digital repository context in particular, so that we can "hide everything but the benefits"; the application of information and communication technology in education and training.

\section{Introduction}

With the rapid development of the internet, user services for resource discovery and retrieval have been greatly enhanced also in the area of education. One of the key activities in education is to author and share resources for teaching and learning. Today, the education community is making available learning content over the internet in digital format at an unprecedented rate (Miller, 2001). But, the establishment of information systems for education, which are capable of storing large amounts of data and making them available to vast user populations in remote locations, raises problems in the ease of searching and retrieving this information. As more and more learning resources become available, it becomes increasingly difficult to search, discover and retrieve the ones that are most useful and relevant for a specific educational purpose (Miller, 2001). The use of education metadata could greatly improve this situation by enhancing the reuse and repurposing of learning materials from one system to another while maintaining interoperability with the user environment (Robson, 2001). Educational tools with appropriate metadata could even

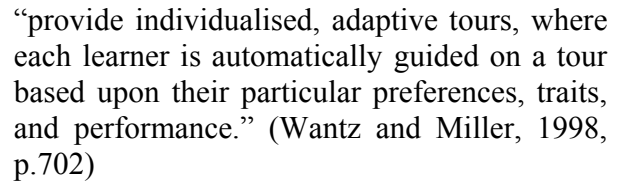

Today, digital educational content is offered by a multitude of portals and other mechanisms using a wide range of standards and specifications (Miller, 2001). With the release of the Dublin Core Metadata Element Set (ANSI/NISO, 2001; ISO, 2003) and the proposed education extension (Sutton and Mason, 2001) or the publication of the IEEE 1484.12.1-2002 standard for Learning Object Metadata (LOM) (IEEE, 2002), international standards have been established for the description of digital learning resources. However, these specifications tend to be refined and extended to address special local requirements. In fact, implementers often need to incorporate different sets of metadata to match the specific needs of their organisation. In this case, a single set of metadata such as the IEEE LOM may not serve the specific needs of an organisation.
For this reason, application profiles have been developed to provide a mechanism of combining data elements from different namespaces (Heery and Patel, 2000).

This problem applies also to the learning resources for agricultural education and training developed and disseminated by the Consultative Group on International Agricultural Research (CGIAR). ${ }^{1}$ The CGIAR, established in 1971, is a strategic partnership of over 60 members, which support 15 international agricultural research centres located in Africa, Asia, Latin America, the USA and Europe. The knowledge generated by the research of the CGIAR Centers as well as the resulting learning resources for capacity building are made widely available to individuals and organisations working for sustainable agricultural development throughout the world (CGIAR Science Council, 2005). This paper describes the efforts to standardise the metadata descriptions of these agricultural learning resources through the development of an application profile, called CG LOM Core, based on IEEE LOM and their dissemination in a repository ${ }^{2}$ in collaboration with the ARIADNE (Alliance of Remote Instructional Authoring and Distribution Networks for Europe) Foundation. ${ }^{3}$ The paper is seen as a contribution to one of the research issues of the LOM research agenda proposed by Duval and Hodgins (2003), that is, application profiles, in particular the adaptation of educational metadata to local specifications, while respecting broader interoperability requirements (Friesen et al., 2002).

\section{Background}

The overall goal of the agricultural research conducted by the CGIAR is to improve the livelihood of low-income people in developing countries through reduced poverty, food insecurity, malnutrition, gender inequality, and child mortality, to help cope with HIV/AIDS, and to foster better institutions, policies and sustainable management of natural resources of particular importance to agriculture and poor people. The CGIAR is a provider of international public goods through agricultural research aimed at alleviating poverty. Capacity building is a key activity to meet the overall goals of the CGIAR. It provides opportunities for 
capacity strengthening to enhance innovation and learning of knowledge-intensive organisations in developing countries, for instance, through the development of tools and methods for knowledge management and structured approaches to needs-based training (CGIAR Science Council, 2005).

Already in the mid-1990s, the CGIAR has recognised the important role of knowledge management and knowledge sharing at a strategic level to strengthen the effective acquisition and exchange of information and knowledge in the CGIAR (CGIAR Center Directors' Committee on Information, Documentation and Training, 1994). Since then, the CGIAR has improved the access to its global public information goods with a strong focus on content and knowledge sharing (Rudgard et al., 2007). In the early 2000s, the CGIAR has established the Information and Communications Technology-Knowledge Management (ICT-KM) Program ${ }^{4}$ with the goal to provide its information users worldwide with simple but enhanced access to the vast array of scientific data, information and knowledge (CGIAR System Office, s.t. [2006]). The ICT-Program supports various projects in the use of ICTs in research, but also in human capacity building activities. One of the activities funded by this program is the Online Learning Resources (OLR) project that was started in 2003 and involved most of the training officers of the 15 CGIAR Centers (Zschocke and Beniest, 2007; Paisley, 2006). The goal of this project was to make CGIAR learning resources - being global public goods - more easily accessible to all intended users following internationally recognised standards and procedures. This project also aimed at creating a CGIAR training community of practice that works closely together for the benefit of an international learning community interested in agriculture and natural resources management.

To better describe the agricultural learning resources of the CGIAR, the project developed an application profile based on IEEE LOM (Beniest et al., 2005). Just recently, the OLR project concluded another phase during which it established a quality assurance system based on the ISO 19796-1 standard with protocols for quality management of learning, education and training (ISO, 2005). These activities complement the recommendations made in a recent evaluation study about the training activities of the CGIAR Science Council (2006). The authors of the study report recommended exploiting more strategically the advantages of Information and Communications Technologies (ICTs) to improve its efficiency by complementing the practical learning components of human capacity building with e-learning tools and methods.

At the time of start of the OLR project, each centre developed and disseminated its own learning resources on the Web. The CGIAR did not have a mechanism to make these resources accessible from a single location. The individual centres structured and made accessible their training resources in different ways. Some of them set-up a separate system for these resources in addition to its general library catalogue, e.g., the joint Cereal Knowledge Bank $^{5}$ of the International Rice Research Institute (IRRI) and the International Maize and Wheat Improvement Center (CIMMYT). The community of CGIAR training officers realised that it would be more effective and efficient if their resources could be retrieved using a standardised description to overcome the fragmentation in providing agricultural learning resources by the different centres. The goal was to find a mechanism to catalogue existing learning resources, review and add new resources, and archive and preserve the CGIAR resources for agricultural education and training for the general public.

To improve access to the shared set of core metadata used for improved discovery and retrieval of CGIAR learning resources, the OLR project decided to adapt the IEEE LOM standard. The goal of applying a shared set of core metadata elements was to allow the federated search of training related documents across all CGIAR Centers as well as its interoperability across the centres and with external entities.

The OLR project explored various existing repositories and their metadata descriptions to identify an approach that would best fit the needs of the CGIAR. The OLR project consulted the Agricultural Metadata Element Set (AgMES) ${ }^{6}$ of the Food and Agricultural Organization (FAO) of the United Nations, with whom the CGIAR collaborates very closely. AgMES is a metadata standard for the description and discovery of agricultural resources. AgMES defines the elements and refinements that are extensions of the Dublin Core Metadata Initiative (DCMI) and the Australian Government Locator Service (AGLS). Because of the educational nature of its materials, the OLR project decided to explore different application profiles that used IEEE LOM or Dublin Core, among others:

- $\quad$ BioSci Education Network (BEN), part of the National Science Digital Library: ${ }^{7}$ The BEN metadata specification is built on the IEEE LOM

- CanCore Learning Resource Metadata Initiative: ${ }^{8}$ CanCore is based on and fully compatible with IEEE LOM

- $\quad$ The former Context e-Learning with Broadband Technologies (CELEBRATE), ${ }^{9}$ coordinated by the European Schoolnet until 2004: The Celebrate Application Profile is based on IEEE LOM

- Curriculum Online ${ }^{10}$ of the UK Department for Children, Schools and Families: The Curriculum Online metadata scheme is based on IEEE LOM

- Education Network Australia (EdNA): ${ }^{11}$ EdNA resources metadata application profile includes elements taken from the DCMI along with EdNA elements as well as elements from the AGLS

- Health Education Assets Library (HEAL), ${ }^{12}$ part of the National Science Digital Library: the HEAL metadata elements description includes selected elements of the LOM metadata standard 
- The European Learning Resource Exchange (LRE, formerly Federation of Internet Resources for Education $)^{13}$ of the European Schoolnet: The EUN Learning Resource Exchange Metadata Application Profile is based on IEEE LOM

- Metadata Ecology for Learning and Teaching $\left(\right.$ MELT) ${ }^{14}$ of the European Schoolnet and the ARIADNE Foundation: the metadata application profile of the MELT project is compatible with the EUN LRE application profile, which in turn is compatible with IEEE LOM

- UK Learning Object Metadata Core (UK LOM Core), ${ }^{15}$ formerly UK Common Metadata Framework: UK LOM Core is essentially an application profile of IEEE LOM

The goal of reviewing different LOM application profiles was to identify mandatory elements used in the implementation of other organisations. This helped to understand better which subset of elements were typically used to describe the basic characteristics of learning resources and how that could guide the development of the CGIAR application profile for its learning materials. Owing to the distributed nature of the CGIAR Centers and the international context of its work, support for multiple languages was considered essential as well.

During this process, the OLR project approached ARIADNE to get support in developing the application profile. ARIADNE had already developed its own application profile for learning objects (Duval et al., 2000, 2001; Najjar et al., 2003). The ARIADNE educational metadata specification is a profile of IEEE LOM and is fully compatible with it. The educational metadata was one of the most innovative original outputs of ARIADNE, which later became one of the foundations of the IEEE LOM. The educational metadata descriptions are stored along with the actual learning resources in ARIADNE's Knowledge Pool System (KPS). This system was developed to create curricula from a generic model by retrieving content materials from the indexed KPS and to reuse existing educational documents for creating new courses and related materials (Duval et al., 2001; Forte et al., 1997a, 1997b).

The OLR project used the core tool of ARIADNE's infrastructure for its repository for the discovery of CGIAR learning resources. Digital repositories contain content that has been deposited by the content creator, owner or a third party on their behalf. A repository is a shared database of information about engineered artefacts, such as software documents, maps, etc., managing both content and its metadata (Bernstein, 1998). In general, a repository offers a minimum set of basic services; it must be sustainable and trusted, well-supported and well-managed (Heery and Anderson, 2005).

As a result of the collaboration with ARIADNE, the OLR project could build upon its experience to develop an application profile based on IEEE LOM for CGIAR learning materials and store these resources in the repository using the KPS technology. The mandatory and optional elements of the CG LOM Core are shown in Table 1.

Table 1 Comparison of IEEE LOM and CG LOM Core indicating the mandatory and optional elements

\begin{tabular}{|c|c|c|c|}
\hline \multirow[b]{2}{*}{ No. } & \multirow[b]{2}{*}{ LOM XML element name } & \multicolumn{2}{|c|}{ CG LOM Core elements } \\
\hline & & Mandatory & Optional \\
\hline 1 & general & & \\
\hline 1.1 & identifier & $\mathrm{x}$ & \\
\hline 1.1 .1 & catalog & $\mathrm{x}$ & \\
\hline 1.1 .2 & entry & $\mathrm{x}$ & \\
\hline 1.2 & title & $\mathrm{x}$ & \\
\hline 1.3 & language & $\mathrm{x}$ & \\
\hline 1.4 & description & & $\mathrm{x}$ \\
\hline 1.5 & keyword & & $\mathrm{x}$ \\
\hline 1.6 & coverage & & $\mathrm{x}$ \\
\hline 1.7 & structure & & $\mathrm{x}$ \\
\hline 1.8 & aggregationLevel & & $\mathrm{x}$ \\
\hline 2 & lifeCycle & & \\
\hline 2.1 & version & & $\mathrm{x}$ \\
\hline 2.2 & status & & $\mathrm{x}$ \\
\hline 2.3 & contribute & & $\mathrm{x}$ \\
\hline 2.3 .1 & role & & $\mathrm{x}$ \\
\hline 2.3 .2 & entity & & $\mathrm{x}$ \\
\hline 2.3 .3 & date & & $\mathrm{x}$ \\
\hline 3 & metaMetadata & & \\
\hline 3.1 & identifier & $\mathrm{x}$ & \\
\hline 3.1 .1 & catalog & $\mathrm{x}$ & \\
\hline 3.1 .2 & entry & $\mathrm{x}$ & \\
\hline 3.2 & contribute & $\mathrm{x}$ & \\
\hline 3.2 .1 & role & $\mathrm{x}$ & \\
\hline 3.2 .2 & entity & $\mathrm{x}$ & \\
\hline 3.2 .3 & date & $\mathrm{x}$ & \\
\hline 3.3 & metadataSchema & $\mathrm{x}$ & \\
\hline 3.4 & language & $\mathrm{x}$ & \\
\hline 4 & technical & & \\
\hline 4.1 & format & & $\mathrm{x}$ \\
\hline 4.2 & size & & $\mathrm{x}$ \\
\hline 4.3 & location & & $\mathrm{x}$ \\
\hline 4.4 & requirement & & $\mathrm{x}$ \\
\hline 4.4 .1 & orComposite & & $\mathrm{x}$ \\
\hline 4.4.1.1 & type & & $\mathrm{x}$ \\
\hline 4.4.1.2 & name & & $\mathrm{x}$ \\
\hline 4.4.1.3 & minimumVersion & & $\mathrm{x}$ \\
\hline 4.4.1.4 & maximumVersion & & $\mathrm{x}$ \\
\hline 4.5 & installationRemarks & & $\mathrm{x}$ \\
\hline
\end{tabular}


Table 1 Comparison of IEEE LOM and CG LOM Core indicating the mandatory and optional elements (continued)

\begin{tabular}{|c|c|c|c|}
\hline \multirow[b]{2}{*}{ No. } & \multirow[b]{2}{*}{ LOM XML element name } & \multicolumn{2}{|c|}{ CG LOM Core element } \\
\hline & & Mandatory & Optional \\
\hline 4 & technical & & \\
\hline 4.6 & otherPlatformRequirements & & $\mathrm{x}$ \\
\hline 4.7 & duration & & $\mathrm{x}$ \\
\hline 5 & educational & & \\
\hline 5.1 & interactivityType & $\mathrm{x}$ & \\
\hline 5.2 & learningResourceType & $\mathrm{x}$ & \\
\hline 5.3 & interactivityLevel & $\mathrm{x}$ & \\
\hline 5.4 & semanticDensity & & $\mathrm{x}$ \\
\hline 5.5 & intendedEndUserRole & $\mathrm{x}$ & \\
\hline 5.6 & context & $\mathrm{x}$ & \\
\hline 5.7 & typicalAgeRange & & $\mathrm{x}$ \\
\hline 5.8 & difficulty & & $\mathrm{x}$ \\
\hline 5.9 & typicalLearningTime & & $\mathrm{x}$ \\
\hline 5.10 & description & & $\mathrm{x}$ \\
\hline 5.11 & language & & $\mathrm{x}$ \\
\hline 6 & rights & & \\
\hline 6.1 & cost & $\mathrm{x}$ & \\
\hline 6.2 & copyrightAndOtherRestrictions & $\mathrm{x}$ & \\
\hline 6.3 & description & $\mathrm{x}$ & \\
\hline 7 & relation & & \\
\hline 7.1 & kind & & $\mathrm{x}$ \\
\hline 7.2 & resource & & $\mathrm{x}$ \\
\hline 7.2 .1 & identifier & & $\mathrm{x}$ \\
\hline 7.2.1.1 & catalog & & $\mathrm{x}$ \\
\hline 7.2.1.2 & entry & & $\mathrm{x}$ \\
\hline 7.2 .2 & description & & $\mathrm{x}$ \\
\hline 8 & annotation & & \\
\hline 8.1 & entity & & $\mathrm{x}$ \\
\hline 8.2 & date & & $\mathrm{x}$ \\
\hline 8.3 & description & & $\mathrm{x}$ \\
\hline 9 & classification & & \\
\hline 9.1 & purpose & $\mathrm{x}$ & \\
\hline 9.2 & taxonPath & $\mathrm{x}$ & \\
\hline 9.2 .1 & source & $\mathrm{x}$ & \\
\hline 9.2 .2 & taxon & $\mathrm{x}$ & \\
\hline 9.2 .2 .1 & id & $\mathrm{x}$ & \\
\hline 9.2 .2 .2 & entry & $\mathrm{x}$ & \\
\hline 9.3 & description & & $\mathrm{x}$ \\
\hline 9.4 & keyword & & $\mathrm{x}$ \\
\hline
\end{tabular}

\section{Conceptual framework}

The use of metadata has grown tremendously in the past four decades. Today, metadata and their management have become critical to bind many different resources of an organisation by holding the metadata along with the actual content data. The use of metadata management tools - also known as (asset) repositories - now becomes crucial (Sen, 2004). Metadata and corresponding repositories have now also expanded in the educational sector. Educational metadata can significantly enhance the effective description, search and retrieval of learning objects resulting in efficient organisation of educational resources for technology-enhanced learning (Giordano, 2000; Graves, 2000). Over the years, different specifications have been developed, which limit the interoperability of systems in their use of different specifications that define the structure of the learning resources. In fact, repositories of LOM should also be able to interoperate not only with one another, but also with other digital repositories developed for purposes other than education (Godby, 2004).

IEEE LOM is an international standard, which provides some consolidation to the field of educational metadata while maintaining flexibility (Duval and Hodgins, 2006; Duval and Robson, 2001). The IEEE LOM has its origins in the metadata specification efforts of both the original ARIADNE and Instructional Management Systems (IMS) Projects, and builds on the metadata work done by the DCMI. On the one hand, each LOM data element is optional. On the other hand, IEEE LOM standardises how to structure metadata about learning objects, while not prescribing which data elements would have to be included.

In the context of the IEEE LOM standard, a learning object is defined as any entity - digital or non-digital - that may be used for learning, education, or training. To share and reuse content components, learning objects are critical, while at the same time systems for the adequate search and retrieval of these objects are needed (Neven and Duval, 2002). In the case of the IEEE LOM base schema, a metadata instance for a learning object describes relevant characteristics of the learning object to which it applies. These characteristics may be grouped according to the nine categories of IEEE LOM, that is, general (to describe the resources as a whole); life cycle (to describe features related to the history and the current state of the resource); meta-metadata (to present information about the metadata record); technical (for technical requirements and characteristics); educational (to describe the instructional and pedagogic characteristics); rights (for the intellectual property rights and conditions of use); relation (to describe the relationship between the resource and other resources); annotation (to include comments about the resource); classification (categories to describe the classification system to which the resource belongs).

Metadata includes both subjective and objective data (Duval et al., 2002). While some of the metadata is clearly objective, such as authorship, date of creation, or version, which could be generated automatically, other metadata is subjective as it requires some judgement as to what values need to be entered (e.g., taxonomy, keywords, summary of content, etc.). 
Because of the proliferation of different interpretations of a standard, the potential for interoperability in the future may be limited. Developing and using international learning technology standards such as IEEE LOM helps to maintain a certain level of interoperability (Duval, 2001, 2004). Using application profiles from a base standard provides another option to address the interoperability of different implementations of a single standard adapted to the needs of different organisations (Duval et al., 2006; Najjar et al., 2003). Application profiles have been implemented that permit implementers to combine different metadata schemas to match the needs of an organisation (Sampson, 2004). An application profile specifies the metadata elements and value sets, combining metadata elements as well as their related value sets from one or more metadata standards. The purpose of an application profile is to adapt or combine existing schemas into a package that is tailored to the functional requirements of a particular application, while retaining interoperability with the original base schemas (Duval et al., 2002; Heery and Patel, 2000).

There are certain principles that guide this process (Duval et al., 2002; Sutton and Mason, 2001). Metadata are modular structures in that they permit to include data elements from different schemas. Metadata systems can be extended to include additional elements that are not part of the base schema. Metadata elements can be refined through qualifiers to redefine the meaning of an element and the definition of the range of values for a given element so that the needs of a specific context can be better addressed. Metadata architectures need to support language and culture differences through the processes of internationalisation and localisation.

In recent years, possibly due to the growing interest in educational metadata the number of implementations requiring either IEEE LOM or Dublin Core has expanded and there has been increased activity in the standards and application profiling arena, leading to new initiatives (Currier, 2008). Both IEEE LOM and Dublin Core have shown a growth in practical implementations. Various communities of interest and organisations have tried to achieve some measure of interoperability through the development of a number of application profiles based on IEEE LOM, e.g., CanCore and the UK LOM Core. IEEE LOM is being reaffirmed by IEEE as a standard. In addition, two additional parts are under development,

- to express IEEE LOM instance using the Dublin Core abstract model

- $\quad$ to develop a Resource Description Framework (RDF) for IEEE LOM data elements.

Similarly, within Dublin Core, the preparation of the DC application profile for education is still in progress. For instance, the FAO is currently working on adapting educational metadata based on the Dublin Core to its learning resources (Stuempel et al., 2007). The reason for the FAO to use Dublin Core instead of IEEE LOM was that a large amount of FAO's learning resources already have a metadata record in one of FAO's repositories described using the AGRIS application profile, which is based on the Dublin Core and the AgMES.

There is a greater need for some kind of harmonisation between the Dublin Core and IEEE LOM models. Although with the development of IEEE LOM progress has been made in harmonising LOM, the proliferation of different metadata specifications still causes issues with respect to metadata interoperability and harmonisation, especially between IEEE LOM and Dublin Core, in particular in the areas of identification/conventions, abstract models, vocabularies, application profiles and syntaxes. As the authors of a study of the European Commission's ProLEARN Harmonisation of Metadata project (Nilsson, 2008) point out, implementers of educational metadata often need to work with more than one specification, which leads to increased complexity of their implementation.

Finally, the ISO is in the process of preparing a new multipart standard for educational metadata, called ISO/IEC 19788 Metadata for Learning Resources (MLR). The goal is to achieve compatibility with both IEEE LOM and Dublin Core ISO 15836 so that users of these standards can migrate to this multipart standard in an efficient and cost-effective manner.

\section{The CG LOM application context}

The OLR project developed its application profile for learning resources, the CG LOM Core, to facilitate the sharing and reuse of its learning resources with its partners (Beniest et al., 2005). The decision to use the IEEE LOM was made because the CGIAR did not have a standard way of describing its resources, including those labelled as learning resources. Each CGIAR Center maintains its own catalogue and system to manage the metadata. By using the IEEE LOM the OLR intended to establish an international standard that could be used across the CGIAR system as a whole, to work towards interoperability within the CGIAR but also to maintain interoperability with external learning object repositories. The development of the CG LOM Core followed the recommendations in available guidelines and their application using the following steps (CEN, 2006; Duval et al., 2006; Knapp et al., 2004):

- It is important to have an explicit understanding of the requirements of a particular context that need to be supported. An organisation needs to define the scope and purpose, stating what the metadata are going to be used for. In the case of the OLR project, the application profile was developed to facilitate the sharing and reuse of its learning resources for agricultural education and training of the CGIAR Centers with its partners. By implementing the LOM into the ARIADNE KPS the OLR project was able to facilitate the search and retrieval of its materials. In addition, it permitted federated searches by its inclusion in the Global 
Learning Objects Brokered Exchange (GLOBE), ${ }^{16}$ thus reaching a much wider audience than initially planned.

- Once the implementer has specified the requirements, then the data elements need to be selected from a schema that has a scope and purpose similar to that of the application profile. In the context of education, the IEEE LOM provides the basic data elements to begin with. Because of the educational nature of the CGIAR materials, the OLR project decided to use the metadata elements of the IEEE LOM.

- Once the data elements have been selected, the implementers can reduce the size of a data element, or maintain it equal to the value of the base standard. The IEEE LOM defines smallest permitted maximum, that is, the smallest number of occurrences of a field that an application profile should support. The CG LOM core has maintained the number and size of the data elements equal to the values in the base standard.

- In principle, an implementer can choose more than one base metadata schema for the proposed application profile. In the case of the CG LOM Core, the implementers just use the IEEE LOM as the base metadata schema.

- In addition to the ability of combining data elements from different sources, an implementer can also include local data elements provided by the base standard. The CG LOM Core has not added local data elements to the base standard, though it notes that this option could be used in the future, especially if an individual centre would have to adapt the profile to address more specific local requirements in a cascading fashion.

- Once the full set of metadata elements has been selected for the proposed application profile, the implementer can now decide about the status of the individual elements. The options that are available usually include mandatory, conditional, recommended, and optional. The implementer has the liberty to impose more stringent obligations on the selected data elements than prescribed by the base standard, but s/he cannot relax the prescriptions of the base standard. The implementers of the CG LOM Core decided to make the following elements mandatory according to the prescription in the base standard (see Figure 1): general, life cycle, meta-metadata, educational, rights, and classification.

- Each data element has a defined value space, that is, the set of values that a data element may contain. Again, the implementer can be flexible in applying greater restrictions than the base standard, but s/he cannot be less restrictive. In addition to the value spaces recommended in the base standard, the CG LOM Core has made suggestions to change the original, which were appropriate, e.g., for the elements 5.2:Learning ResourceType and 5.5:IntendedEndUserRole, to better reflect the specific requirements of the CGIAR. For instance, the learning resource type has been revised to include additional elements such as expository texts, procedural texts, advance organiser, etc. In the case of the intended end-user role, the CG LOM Core includes additional element such as trainers, adult educators, adult students, university students, etc. In addition, the CG LOM Core has included for element 9.2:TaxonPath the AGRIS subject categories and the controlled vocabulary of the AGROVOC of the FAO as a Web service for classifying the content with the controlled vocabulary used in the agricultural domain.

- The implementer can also define the relationships and dependencies between data elements in an application profile. The CG LOM Core has maintained the inter-relationships provided by the base standard, e.g., element 5.2:EducationalLearningResourceType depends on the value of element 5.1:Educational InteractivityType.

- The application profile defines the data type of an element, for instance, LangString, DateTime, Duration, Vocabulary, etc., as well as the rules on how to apply these data types. The CG LOM Core uses the rules for data types as prescribed by the base standard.

- Finally, the implementer needs to ensure that any instance that conforms to the relevant binding of the base standard also conforms to the binding of the application profile. To ensure the interoperability between different application profiles based on IEEE LOM, the data element names of the CG LOM Core conform to the corresponding names in the base standard.

Figure 1 CG LOM Core structure, highlighting the mandatory data elements

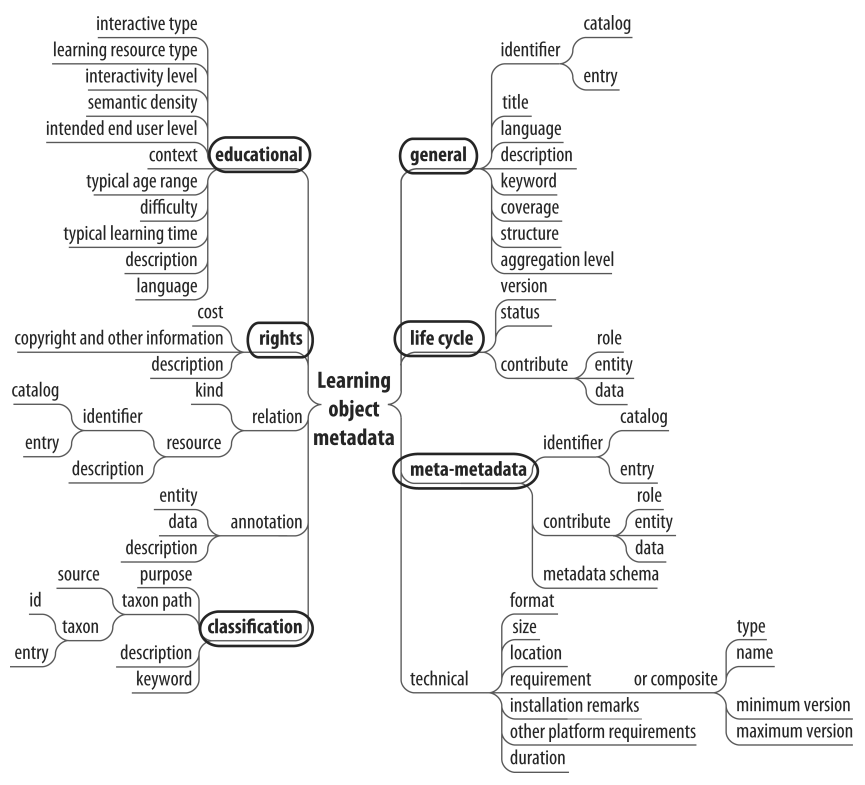


The OLR repository has also been integrated with an open source Learning Management System (LMS), Moodle. Course developers are able to retrieve learning objects from the repository into the LMS through a specialised search function. ARIADNE has developed a service-oriented architecture consisting of three independent subsystems that permit the communication between a LMS and a repository (Broisin et al., 2005). The central component is a bridge that binds the LMS and the repository. It is designed in such a way that it can be accommodated to any PHP-based LMS. This architecture permits a course developer to query the repository from inside the LMS and to retrieve the metadata of the required learning resources. The learning resource can be downloaded to the local host and transferred from the repository into the LMS. The OLR project has made available the repository alongside with the LMS. Courses have been developed that utilise this feature, thus encouraging the sharing and reuse of learning resources further.

\section{Application profile implementation issues}

Although the OLR project succeeded in establishing an application profile to describe its learning resources, it has not achieved a critical mass, yet. Also, many learning resources in the repository only have a limited set of metadata associated with them where they were not mandatory. The creation of the metadata was limited by the issue of the manual entry of the data.

Although some of the metadata is mandatory, most of them do not have to be provided by the end-user and are entered automatically. Research on automatic metadata generation indicates that metadata can be retrieved from four main sources, that is, document content, document context, document usage, and document structure (Cardinaels et al., 2005). Because end-users generally do not take the time to generate metadata, using automatically generated metadata will help to maintain consistency and reliability. The process of automatically generating metadata can be extended with the notion of an ecological approach to the continuous collection of metadata based on end-user experiences with learning objects in an adaptable environment (Brooks and McCalla, 2006). According to this approach, metadata inform a reasoning process over a learning object to determine automatically its suitability for a given purpose and learner.

Within the context of the OLR project many objective (or technical) metadata of the learning resources have been generated automatically. With the creation of user profiles for metadata implementers much of the meta-metadata information has been generated automatically without the notice of the individual. But the management of subjective metadata, especially on the educational context, has not been fully utilised.

With regards to the learning objects stored in the repository, more work is still needed to arrive at an appropriate document granularity. Learning resources should be designed for reuse. Once they are developed as self-contained documents they can be integrated in new learning contexts. For instance, the integration of the OLR repository with a LMS demonstrates how the resources can be reused in the context of a course. Smaller documents are more reusable because they contain less educational context information. However, while the reuse of these resources may increase, they have less value to the end-user because they lack the additional descriptive information.

At the moment, the OLR repository includes a great variety of learning resources, which may not necessarily correspond with the general notion of a learning object. To achieve more consistency and reliability in the generation and use of learning objects, the OLR intends to implement other standards in the development of learning resources. For instance, using Sharable Content Object Reference Model (SCORM) compliant content based on the IMS content packaging specification would permit to incorporate the learning resources more easily into both the repository and the LMS. As research of ARIADNE (Broisin et al., 2005) has shown, metadata can be automatically extracted from a SCORM manifest file and mapped to the CG LOM Core and automatically inserted into the repository. This would greatly enhance the reusability of the learning resources not only within the CGIAR, but also by partners who are using systems that support the standards.

To make the CG LOM Core more accessible to others, the OLR project intends to encode and publish the application profile both as an XML Document Type Definition (DTD) as well as an RDF schema. The existing guidelines for developing application profiles (CEN, 2006; Duval et al., 2006) need to be adapted to the CG LOM Core and properly documented to assist implementers and other users. At the same time it seems beneficial to register the CG LOM Core with some kind of an authoritative registry to better monitor its maintenance and to further its use (Baker et al., 2001; Onyancha et al., 2001), which would also help to enhance the automatic generation of metadata (Hillmann and Phipps, 2007).

Further research would be needed to monitor the impact of the CG LOM Core for agricultural learning resources. This would help to make refinements of the application profile and to further promote the use of educational metadata by the CGIAR and its partners, for instance, in a cascading fashion (Duval et al., 2006). The latter would also help to adapt the application profile to the needs of specific educational settings, e.g., higher agricultural education as opposed to non-formal education or technical vocational education.

Finally, the workflow for developing quality digital learning objects needs to be further elaborated. Because of the wide range of objects uploaded to the OLR repository and the need to have more consistently structured documents to enhance the retrieval of metadata, the OLR project intends to further implement the quality assurance protocols based on ISO 19796. In general, the importance of quality assurance system for learning objects and corresponding metadata is recognised (Barton et al., 2003; Hillmann and Phipps, 2007). To measure the quality of metadata, categories such as completeness, 
accuracy, provenance, conformance to expectations, logical consistency and coherence, timeliness, and accessibility can be used. However, the technical infrastructure needed to establish a quality assurance system is still a major issue for the OLR project.

\section{Conclusion}

Noticing that CGIAR Centers also make available learning resources in their own customised portal sites, such as the Cereal Knowledge Bank of IRRI and CIMMYT, ${ }^{17}$ it is crucial to provide a mechanism that would provide additional access to these resources from a central location such as the OLR repository without duplicating the effort of uploading the materials. The OLR project is now investigating to implement a mechanism to collect the metadata from these additional repositories of the CGIAR using a protocol for metadata harvesting such as the one of the Open Archives Initiative. ${ }^{18}$ Thus, the OLR portal would not only serve as a repository of learning resources that have been stored on the site, but also as a referatory by managing the metadata that refer to digital learning resources stored on other sites of the CGIAR.

Making resources available and accessible for agricultural research and education is a major contribution to strengthening the capacities in developing countries. Web-based metadata and data repositories help to enhance the provision of critical knowledge and information, ranging from open agricultural research systems (Schweik et al., 2005) to large document repositories such as AGRIS of the FAO (Onyancha et al., 2001; Rudgard et al., 2007) using an agricultural metadata framework and corresponding application profile for resource discovery. The CG LOM Core is a contribution to these developments. The integration of a learning object repository with an open source LMS allows the CGIAR training community as well as its partners to utilise the CGIAR learning resources. The option of federated searches through GLOBE has permitted the CGIAR to make its learning resources available to an even wider audience. But with the pending technical issues and the need for further research on using learning technology to strengthen human capacities in the agricultural sector in developing countries, it is vital for the CGIAR to stay engaged in international research networks that study these issues, such as the Agricultural Learning Repositories Task Force, ${ }^{19}$ and to continue the collaboration with strategic partners such as ARIADNE.

\section{Acknowledgements}

The CGIAR On-line Learning Resources (OLR) project is a collaborative project involving several CGIAR Centers with funding from the World Bank through the CGIAR ICT-KM Program. The project is further implemented in close collaboration with the ARIADNE Foundation and the United Nations University Institute for Environment and Human Security (UNU-EHS).

\section{References}

ANSI/NISO (2001) ANSI/NISO Z39.85-2001. The Dublin Core Metadata Element Set, National Information Standards Organization (NISO) Press, Bethesda, MD.

Baker, T., Dekkers, M., Heery, R., Patel, M. and Salokhe, G. (2001) 'What terms does your metadata use? Application profiles as machine-understandable narratives', Journal of Digital Information, Vol. 2, No. 2, p.10, Article No. 65, 2001-11-06, http://jodi.tamu.edu/Articles/v02/i02/Baker/

Barton, J., Currier, S. and Hey, J.M.N. (2003) 'Building quality assurance into metadata creation: An analysis based on the learning objects and e-prints communities of practice', Proceedings of the International Conference on Dublin Core and Metadata Applications (DC-2003), 28 September-2 October, Seattle, WA, USA, p.10, http://dcpapers.dublincore.org/ojs/pubs/article/view/732

Beniest, J., Paisley, C. and Zschocke, T. (2005) Learning Object Metadata (LOM) Core, (Available from World Agroforestry Centre (ICRAF), United Nations Avenue, POBox 30677, 00100 Nairobi, Kenya), May, p.52.

Bernstein, P.A. (1998) 'Repositories and object oriented databases', ACM SIGMOD Record, Vol. 27, No. 1, pp.88-96.

Broisin, J., Vidal, P., Meire, M. and Duval, E. (2005) 'Bridging the gap between learning management systems and learning object repositories: exploiting learning context information', Proceedings of the Advanced Industrial Conference on Telecommunications/Service Assurance with Partial and Intermittent Resources Conference/E-Learning on Telecommunications Workshop, 17-20 July, Lisbon, Portugal, pp. $478-483$.

Brooks, C. and McCalla, G. (2006) 'Towards flexible learning object metadata', International Journal of Continuing Engineering Education and Lifelong Learning, Vol. 16, Nos. 1-2, pp.50-63.

Cardinaels, K., Meire, M. and Duval, E. (2005) 'Automating metadata generation: The simple indexing interface', Proceedings of the 14th International Conference on World Wide Web, 10-14 May, Chiba, Japan, pp.548-556.

CEN (2006) Guidelines and Support for Building Application Profiles in E-Learning (CEN Workshop Agreement, CWA 15555:2006), CEN, European Committee for Standardization, Brussels, BE, ftp://ftp.cenorm.be/PUBLIC/CWAs/e-Europe/ WS-LT/cwa15555-00-2006-Jun.pdf

CGIAR Center Directors' Committee on Information, Documentation and Training (1994) The Future of Information Activities in the CGIAR: A System-Wide Strategy, CGIAR Technical Advisory Committee (TAC), Rome, IT, http://www.cgiar.org/corecollection/docs/tc9410b.pdf

CGIAR Science Council (2005) System Priorities for CGIAR Research 2005-2015, Science Council Secretariat (Reprint), Rome, IT, http://www.sciencecouncil.cgiar.org/publications/ pdf/SCPriorities_prFinal(1-r).pdf

CGIAR Science Council (2006) Evaluation and Impact of Training in the CGIAR, Science Council Secretariat, Rome, IT, http://www.sciencecouncil.cgiar.org/publications/ pdf/Evaluation_and_Impact_of_Training.pdf

CGIAR System Office (s.t. [2006]) Global Public Goods: From Data and Information to Food, CGIAR System Office, Chief Information Officer, Rome, IT, http://ictkm.cgiar.org/ investment_plan/GPG_strategy.htm

Currier, S. (2008) 'Metadata for learning resources: an update on standards activity for 2008', ARIADNE, Vol. 55, http://www.ariadne.ac.uk/issue55/currier/ 
Duval, E. (2001) 'Metadata standards: What, who and why', Journal of Universal Computer Science, Vol. 7, No. 7, pp.591-601, http://www.jucs.org/jucs_7_7/metadata standards_what_who

Duval, E. (2004) 'Learning technology standardization: making sense of it all', International Journal on Computer Science and Information Systems, Vol. 1, No. 1, pp.33-43, http://www.comsis.fon.bg.ac.yu/ComSIS/Volume01/InvitedP apers/ErikDuval.htm

Duval, E. and Hodgins, W. (2003) 'A LOM research agenda', Alternate Paper Tracks Proceedings of the 12th International World Wide Web Conference, http://www2003.org/cdrom/ papers/alternate/P659/p659-duval.html.html

Duval, E. and Hodgins, W. (2006) 'Standardized uniqueness: Oxymoron or vision of the future?', Computer, Vol. 39, No. 3, pp.96-98.

Duval, E. and Robson, R. (2001) 'Guest editorial on metadata', Interactive Learning Environments, Vol. 9, No. 3, pp.201-205.

Duval, E., Forte, E., Cardinaels, K., Verhoeven, B., Van Durm, R., Hendrikx, K., Wentland Forte, M., Ebel, N., Macowicz, M., Warkentyne, K. and Haenni, F. (2001) 'The ARIADNE knowledge pool system', Communications of the ACM, Vol. 44, No. 5, pp.73-78.

Duval, E., Hodgins, W., Sutton, S. and Weibel, S.L. (2002) 'Metadata principles and practicalities', D-lib Magazine, Vol. 8, No. 4, pp.1-16, http://www.dlib.org/dlib/april02/ weibel/04weibel.html

Duval, E., Smith, N. and Van Coillie, M. (2006) 'Application profiles for learning', Proceedings of the Sixth International Conference on Advanced Learning Technologies (ICALT'06), 5-7 July, Kerkrade, Netherlands, pp.242-246.

Duval, E., Vervaet, E., Verhoeven, B., Hendrikx, K., Cardinaels, K., Olivié, H., Forte, E.N., Haenni, F., Warkentyne, K., Wentland Forte, M. and Simillion, F. (2000) 'Managing digital educational resources with the ARIADNE metadata system', Journal of Internet Cataloging, Vol. 3, Nos. 2-3, pp.145-171.

Forte, E.N., Wentland Forte, M.H.K. and Duval, E. (1997a) 'The ARIADNE project (Part 1): knowledge pools for computer-based and telematics-supported classical, open and distance education', European Journal of Engineering Education, Vol. 22, No. 1, pp.61-74.

Forte, E.N., Wentland Forte, M.H.K. and Duval, E. (1997b) 'The ARIADNE project (Part 2): knowledge pools for computer-based and telematics-supported classical, open and distance education', European Journal of Engineering Education, Vol. 22, No. 1, pp.153-166.

Friesen, N., Mason, J. and Ward, N. (2002) 'Building educational metadata application profiles', Proceedings of the International Conference on Dublin Core and Metadata for E-Communities, 13-17 October, Florence, Italy, pp.63-69, http://www.bncf.net/dc2002/program/ft/paper7.pdf

Giordano, R. (2000) 'Metadata issues, document architecture, and best educational practices', Journal of Internet Cataloging, Vol. 3, Nos. 2-3, pp.243-261.

Godby, C.J. (2004) 'What do application profiles reveal about the learning object metadata standard?', ARIADNE, No. 41, http://www.ariadne.ac.uk/issue41/godby/
Graves, W.H. (2000) 'Discovering and using educational resources on the internet: Global progress or random acts of progress', Journal of Internet Cataloging, Vol. 3, Nos. 2-3, pp.279-287.

Heery, R. and Anderson, S. (2005) Digital Repositories Review, Unpublished manuscript, UKOLN, University of Bath, Bath, UK, http://www.jisc.ac.uk/uploaded_documents/ digital-repositories-review-2005.pdf

Heery, R. and Patel, M. (2000) 'Application profiles: Mixing and matching metadata schemas', ARIADNE, No. 25, http://www. ariadne.ac.uk/issue25/app-profiles/

Hillmann, D.I. and Phipps, J. (2007) 'Application profiles: Exposing and enforcing metadata quality', Proceedings of the International Conference on Dublin Core and Metadata Applications, 27-31 August, Singapore, pp.52-62, http://www.dcmipubs.org/ojs/index.php/pubs/article/viewFile/ $41 / 20$

IEEE (2002) IEEE Std. 1484.12.1-2002. IEEE Standard for Learning Object Metadata, Institute of Electrical and Electronics Engineers, New York.

ISO (2003) ISO 15836:2003 The Dublin Core Metadata Element Set, International Organization for Standardization, Geneva, $\mathrm{CH}$.

ISO (2005) ISO/IEC 19796-1:2005 Information Technology Learning, Education and Training - Quality Management, Assurance and Metrics - Part 1: General Approach, International Organization for Standardization, Geneva, $\mathrm{CH}$.

Knapp, M., Dexter, S. and McLaughlin, R. (2004) 'Metadata co-development: a process resulting in metadata about technical assistance to educators', Proceedings of the 13th International World Wide Web Conference, 17-22 May, New York City, NY, USA, pp.410-411.

Miller, (2001) 'Towards consensus on educational metadata', ARIADNE, No. 27, http://www.ariadne.ac.uk/issue27/meg/ intro.html

Najjar, J., Duval, E., Ternier, S. and Neven, F. (2003) 'Towards interoperable learning object repositories: The ARIADNE experience', Proceedings of the IADIS International Conference on WWW/Internet 2003, 5-8 November, Algarve, Portugal, Vol. I, pp.219-226.

Neven, F. and Duval, E. (2002) 'Reusable learning objects: a survey of LOM-based repositories', Proceedings of the tenth ACM International Conference on Multimedia, 1-6 December, Juan les Pins, France, pp.291-294.

Nilsson, M. (Ed.) (2008) Harmonization of Metadata Standards, ProLEARN Deliverable D4.7, http://ariadne.cs.kuleuven.be/ lomi/images/5/52/D4.7-prolearn.pdf

Onyancha, I., Keizer, J. and Katz, S. (2001) 'A Dublin core application profile in the agricultural domain', Proceedings of the International Conference on Dublin Core and Metadata Applications, DC-2001, 24-26 October, Tokyo, Japan, pp.185-192.

Paisley, C. (2006) 'Making agricultural training and education resources accessible', International Journal of Education and Development using Information and Communication Technology (IJEDICT), Vol. 2, No. 3, pp.129-130, http:// ijedict.dec.uwi.edu/viewarticle.php?id $=213$ \&layout $=\mathrm{html}$

Robson, R. (2001) 'Pedagogic metadata', Interactive Learning Environments, Vol. 9, No. 3, pp.207-218. 
Rudgard, S., Porcari, E., Adley, N., Chan, L. and Jensen, M. (2007) 'Publishing and disseminating science findings', in Shrum, W., Benson, K.R., Bijker, W.E. and Brunnstein, K. (Eds.) Past, Present and Future of Research in the Information Society, Springer, Heidelberg, DE, pp.183-187.

Sampson, D. (2004) 'The evolution of educational metadata: from standards to application profiles', Proceedings of the IEEE International Conference on Advanced Learning Technologies (ICALT'04), Joensuu, Finland, 30 August-1 September, pp.1072-1073.

Schweik, C.M., Stepanov, A. and Grove, J.M. (2005) 'The open research system: a web-based metadata and data repository for collaborative research', Computers and Electronics in Agriculture, Vol. 47, No. 3, pp.221-242.

Sen, A. (2004) 'Metadata management: past, present and future', Decision Support Systems, Vol. 37, pp.151-173.

Stuempel, H., Salokhe, G., Aubert, A., Keizer, J., Nadeau, A., Katz, S. and Rudgard, S. (2007) 'Metadata application profile for agricultural learning resources', 2nd International Conference on Metadata and Semantics Research (MTSR07), 11-12 October, Corfu, Greece, p.8, ftp://ftp.fao.org/docrep/ fao/010/ai154e/ai154e00.pdf

Sutton, S.A. and Mason, J. (2001) 'The Dublin core and metadata for educational resources', Proceedings of the International Conference on Dublin Core and Metadata Applications 2001, 24-26 October, Tokyo, Japan, pp.25-31.

Wantz, L.J. and Miller, M. (1998) 'Educational metadata in use', Computer Networks and ISDN Systems, Vol. 30, pp.701-702.

Zschocke, T. and Beniest, J. (2006) 'On-line learning resources for international agriculture and natural resources management', ISHS Acta Horticulturae 762: XXVII International Horticultural Congress - IHC2006: International Symposium on Horticultural Plants in Urban and Peri-Urban Life, 13-18 August, Seoul, Korea, pp.393-400.

\section{Notes}

${ }^{1}$ http://www.cgiar.org/

${ }^{2} \mathrm{http} / / /$ learning.cgiar.org/

${ }^{3}$ http://www.ariadne-eu.org/

${ }^{4} \mathrm{http}: / /$ ictkm.cgiar.org/

${ }^{5}$ http://www.knowledgebank.irri.org/

${ }^{6} \mathrm{http}: / / \mathrm{www}$. fao.org/aims/agmes_intro.jsp

${ }^{7}$ http://www.biosciednet.org/

${ }^{8}$ http://www.cancore.ca/

${ }^{9} \mathrm{http}: / /$ celebrate.eun.org/

${ }^{10} \mathrm{http} / /$ www.curriculumonline.gov.uk/

${ }^{11} \mathrm{http}: / /$ www.edna.edu.au/

${ }^{12} \mathrm{http}: / / \mathrm{www} \cdot h$ alcentral.org/

${ }^{13} \mathrm{http} / / /$ fire.eun.org/

${ }^{14} \mathrm{http}$ ://info.melt-project.eu/

${ }^{15} \mathrm{http}: / /$ zope.cetis.ac.uk/profiles/uklomcore

${ }^{16} \mathrm{http}: / /$ www.globe-info.org/

${ }^{17} \mathrm{http} / / /$ www.knowledgebank.irri.org/

${ }^{18} \mathrm{http}$ ://www.openarchives.org/OAI/openarchivesprotocol.html

${ }^{19} \mathrm{http}: / /$ aglr.aua.gr 